\title{
PENCAPAIAN KINERJA PERUSAHAAN KELUARGA MELALUI TINGKAT KESIAPAN SUKSESOR DAN HUBUNGAN ANTAR- ANGGOTA KELUARGA DAN BISNIS
}

\author{
Wahyudi Henky Soeparto \\ Universitas Ciputra Surabaya \\ e-mail: awahyudi@ciputra.ac.id
}

\begin{abstract}
Family businesses are one of the biggest contributors of Indonesia gross domestic product (GDP). Universitas Ciputra facilitate their students with family business guild. Succession plan and communication are important things for family businesses. Family businesses must educate potential successors so that the succession plan can run well. The purpose of this study was to examine the effect of preparation level of heirs towards family business performance; examine the effect of relationships among family and business members towards family business performance.

This study uses a quantitative approach. The population in this study was the Family Business Community Universitas Ciputra with a total sample of 93 people, the sampling technique used in this study was purposive random sampling. The data analysis method used is Partial Least Square (PLS). The results showed that preparation level of heirs variable has a positive and significant effect on family business performance; the relationship among family and business members variable has a positive and significant effect on family business performance.
\end{abstract}

Keywords: family business, family business performance, preparation level of heirs, relationship among family and business members

\section{Pendahuluan}

Bisnis-bisnis entrepreneurship yang berkembang di Indonesia memberikan kontribusi yang signifikan terhadap perkembangan ekonomi negara. Menurut survei Price Waterhouse Cooper (PWC) di tahun 2014 dan 2015, lebih dari 40.000 orang terkaya di Indonesia memiliki perusahaan keluarga dengan omset sekitar 5-10 juta USD dan total kekayaan mencapai 134 juta USD, nilai ini sekitar 25\% dari Produk Domestik Bruto Indonesia (Price Waterhouse Cooper, 2014). Price Waterhouse Cooper (2014) juga mengatakan perusahaan keluarga merupakan salah satu jenis perusahaan yang ada di Indonesia, dan lebih dari 95\% bisnis di Indonesia merupakan bisnis keluarga. Beberapa contoh dari perusahaan keluarga yang terkenal di Indonesia adalah Astra Group, Bakrie Group, Blue
Bird Group, dan Ciputra Group. Ciputra Group sendiri memiliki bisnis dalam sektor pendidikan yaitu Universitas Ciputra.

Universitas Ciputra terkenal dengan visinya untuk "Menjadi universitas yang menciptakan entrepreneur kelas dunia yang berkarakter integritas-profesionalisme-entrepreneurship (IPE) dan kebangsaan serta memberi kontribusi positif bagi bangsa Indonesia”. Sejalan dengan visinya, Universitas Ciputra mendorong setiap bisnis yang dibentuk mahasiswanya untuk berkelanjutan hingga dan tidak lekang oleh waktu. Universitas Ciputra menawarkan program pembelajaran bagi calon penerus perusahaan keluarga dalam Guild Family Business, sebagai salah satu Guild Entrepreneurship. Pembelajaran tentang perusahaan keluarga diberikan kepada mahasiswa yang tergabung di dalamnya. Mahasiswa yang pernah tergabung dalam Guild Family 
Business akan langsung tergabung dalam Family Business Community Universitas Ciputra, sampai sekarang dengan 8 angkatan dan total anggota lebih dari 340 orang. Mayoritas dari mahasiswa Universitas Ciputra yang tergabung dalam guild ini merupakan generasi kedua di perusahaan keluarga mereka masing-masing dengan jenis industri, latar belakang perusahaan, dan daerah asal yang berbeda-beda.

Berbagai macam jurnal membahas tentang definisi dan ciri-ciri perusahaan keluarga, beragam definisi telah dikemukakan oleh para peneliti sebelumnya. Menurut Diéguez-Soto et al. (2015) definisi perusahaan keluarga belum dapat didefinisikan dengan pasti, karena definisi perusahaan keluarga dapat dibedakan dari beberapa kriteria seperti kepemilikan, kontrol, dewan direksi, manajemen, pengakuan perusahaan sendiri, suksesi lintas generasi, generasi ganda, dan nilai-nilai keluarga serta bisnis. Salah satu hal yang membedakan perusahaan keluarga dengan perusahaan non-keluarga adalah relasi dan perspektif tentang generasi penerus (Aronoff \& Ward, 1995).

Walsh (2011) mengatakan bahwa sekitar $70 \%$ perusahaan keluarga tidak dapat bertahan hingga generasi kedua, dan 90\% tidak akan bertahan hingga generasi ketiga. Motwani et al. (2006) mengatakan bahwa rencana suksesi, komunikasi, dan pelatihan merupakan hal yang penting dalam perusahaan keluarga, tanpa memedulikan ukuran dari perusahaan keluarga yang dimiliki. Penelitian juga membuktikan bahwa $85 \%$ pemilik perusahaan keluarga perlu mendidik suksesor potensial perusahaan secara jelas dan tepat.

Proses suksesi yang tidak berjalan dengan baik tidak hanya menimbulkan dampak serius pada hubungan keluarga dan bisnis, namun juga berdampak serius pada perkembangan ekonomi negara, di dalam perusahaan keluarga juga akan ada konflik internal yang dapat mengganggu keberlangsungan proses suksesi (Buang et al., 2013 dalam Mokhber et al., 2017).

Terkait dengan hal di atas, penelitian ini bertujuan untuk mengetahui pengaruh tingkat kesiapan suksesor dan hubungan antar-anggota keluarga dan bisnis terhadap kinerja perusahaan keluarga. Hasil penelitian akan dapat berguna untuk perusahaan keluarga yang tergabung dalam

\section{Tinjauan Pustaka}

\subsection{Perusahaan Keluarga}

Perusahaan keluarga adalah perusahaan yang terdapat paling sedikit dua generasi yang terlibat di dalam kegiatan produksi dan generasi kedua dapat memengaruhi kebijakan perusahaan (Setiawan \& Susanto, 2018). Ciri-ciri yang dimiliki oleh perusahaan keluarga yaitu jumlah saham yang dimiliki oleh anggota keluarga tunggal lebih dari 50\% dan perusahaan dikelola oleh mayoritas anggota keluarga dan pemilik saham mayoritas (Bizri, 2016). Selain definisi yang telah tertulis di atas, definisi perusahaan keluarga juga dapat dibedakan dari beberapa kriteria seperti kepemilikan, kontrol, dewan direksi, manajemen, pengakuan perusahaan sendiri, suksesi lintas generasi, generasi ganda, dan nilai-nilai keluarga serta bisnis (DiéguezSoto et al., 2015).

\subsection{Rencana Suksesi}

Proses suksesi internal dalam bisnis keluarga menjadi permasalahan yang penting dan sangat kompleks (Kamei \& Dana, 2012). Menurut Bozer et al. (2017) ada empat protagonis dalam bisnis keluarga yang dipandang memiliki pengaruh langsung terhadap proses suksesi. Mereka didefinisikan sebagai berikut.

- Generasi pendahulu (incumbent): pendiri dan anggota keluarga yang memegang posisi 
manajemen senior dalam bisnis dan telah melepaskan atau hendak menyerahkan jabatan tersebut kepada anggota keluarga baru.

- Generasi penerus (successor): anggota keluarga yang telah atau akan mengambil alih posisi kepemimpinan dari incumbent.

- Keluarga: anggota keluarga yang terlibat dalam bisnis harus membawa sifat, budaya dan juga nilai yang terkandung di dalam keluarga, terutama dengan menentukan kegiatan manajemen harian dan tujuan strategis perusahaan.

- Anggota non-keluarga: karyawan yang bekerja dalam bisnis.

\subsection{Kinerja Perusahaan Keluarga}

Kinerja perusahaan tentunya menjadi salah satu ukuran utama dalam manajemen dan bisnis. Kinerja perusahaan keluarga sendiri masih memiliki definisi yang belum dapat disetujui bersama oleh para peneliti (Venkatraman \& Ramanujam, 1986). Penelitian yang dilakukan oleh Chu (2011) mengatakan bahwa perusahaan keluarga dengan skala yang lebih kecil memiliki kinerja bisnis yang lebih baik dikarenakan hubungan anggota keluarga yang lebih dekat, di mana hal ini memfasilitasi komunikasi antaranggota keluarga. Definisi luas dari kinerja bisnis sendiri dapat dilihat melalui kinerja finansial dan non-finansial (Mokhber et al., 2017). Indikator tersebut meliputi return on investment (ROI), sales growth, market share, product/service quality, dan operational efficiency (Kim \& Gao, 2013).

\subsection{Hubungan antara Tingkat Kesiapan Suksesor dan Kinerja Perusahaan Keluarga}

Kesiapan suksesor dapat dihubungkan dengan kinerja perusahaan keluarga. Semakin tua usia pemilik, maka pengalaman kerja yang dimiliki akan semakin banyak dan hal ini tentunya berkontribusi terhadap kesuksesan kinerja perusahaan keluarga. Selain itu, dapat dikatakan bahwa pengalaman suksesor di perusahaan luar sebelum masuk ke perusahaan keluarga menjadi aset penting bagi suksesor (Barach \& Ganitsky, 1995). Mokhber et al. (2017) juga menemukan bahwa perusahaan keluarga perlu mengalokasikan anggaran keluarga untuk memastikan suksesor benar-benar siap untuk proses suksesi Berdasarkan kajian literatur di atas maka hipotesis pertama dari penelitian ini adalah tingkat kesiapan suksesor berpengaruh positif dan signifikan terhadap kinerja perusahaan keluarga.

$\mathrm{H}_{1}$ : Tingkat kesiapan suksesor berpengaruh positif dan signifikan terhadap kinerja perusahaan keluarga

\subsection{Hubungan antara Hubungan antar-Anggota Keluarga dan Bisnis}

Hubungan antar-anggota keluarga dan bisnis dalam perusahaan keluarga yang baik sangat penting untuk memastikan keberlanjutan perusahaan keluarga tersebut (Bachkaniwala et al., 2001). Maka dari itu, tiap anggota keluarga harus memercayai satu sama lain dan memiliki komunikasi yang baik, sehingga perusahaan keluarga dapat sukses (Mokhber et al., 2017). Selain itu, komunikasi yang baik antar-anggota keluarga dapat meningkatkan kepuasan dan efektivitas suksesi dalam perusahaan keluarga, sehingga kinerja perusahaan keluarga juga akan baik (Pyromalis \& Vozikis, 2009). Ghee et al. (2015) juga menyatakan bahwa tingkat kepercayaan tinggi dan hubungan erat antar-anggota keluarga dapat membantu proses suksesi yang lebih baik dan meningkatkan kinerja perusahaan keluarga. Berdasarkan kajian literatur di atas, maka hipotesis kedua dari penelitian ini adalah 
hubungan antar-anggota keluarga dan bisnis berpengaruh positif dan signifikan terhadap kinerja perusahaan keluarga.

$\mathrm{H}_{2}$ : Hubungan antar-anggota keluarga dan bisnis berpengaruh positif dan signifikan terhadap kinerja perusahaan keluarga.

\section{Metodologi Penelitian}

Penelitian ini akan dilakukan dengan metode kuantitatif.

\subsection{Populasi dan Sampel}

Populasi dalam penelitian ini adalah anggota dari Family Business Community Universitas Ciputra Surabaya. Teknik pengambilan sampel yang akan digunakan adalah purposive random sampling. Chin (1998) mengatakan bahwa jumlah sampel minimal adalah 10 kali dari besarnya indikator terbanyak dalam sebuah variabel. Pengumpulan data dalam penelitian ini akan menggunakan kuesioner online.

\subsection{Variabel dan Definisi Operasional}

Variabel yang digunakan dalam penelitian ini adalah tingkat kesiapan suksesor $\left(\mathrm{X}_{1}\right)$, hubungan antar-anggota keluarga dan bisnis $\left(\mathrm{X}_{2}\right)$, dan kinerja perusahaan keluarga (Y).

\section{Tingkat Kesiapan Suksesor}

Morris et al. (1996) menyatakan bahwa tingkat kesiapan suksesor dapat dilihat dari kemampuan berbisnis yang sesuai, kemampuan untuk mengatur perusahaan, memiliki pengetahuan operasional perusahaan, dan memiliki sikap baik untuk memastikan operasional perusahaan berjalan dengan lancar. Indikator dalam variabel ini adalah sebagai berikut.

- Education: Tingkat pendidikan akhir suksesor
- Work experience outside family firm: Pengalaman bekerja di luar perusahaan keluarga

- Motivation to join family firm: Motivasi atau dorongan untuk bergabung ke dalam perusahaan keluarga

- Self-perception of preparation: Persepsi individu suksesor tentang kesiapan diri

2. Hubungan antar-Anggota Keluarga dan Bisnis Hubungan antar-anggota keluarga dalam perusahaan keluarga meliputi komunikasi, kepercayaan, komitmen, kesetiaan, kekacauan keluarga, persaingan antar-saudara, kecemburuan satu sama lain, konflik, dan nilai bersama dan tradisi dalam keluarga (Mokhber et al., 2017). Indikator dalam variabel ini adalah sebagai berikut.

- Communication: komunikasi yang terjadi antar-anggota keluarga dan bisnis.

- Trust: kepercayaan yang timbul di antara anggota keluarga dan bisnis.

- Commitment: komitmen untuk bekerja dalam perusahaan keluarga.

- Loyalty: loyalitas dalam hubungan antaranggota keluarga dan bisnis.

- Family turmoil: kekacauan yang timbul dalam keluarga.

- Sibling rivalry: persaingan saudara kandung.

- Jealousy/resentment: kecemburuan atau kebencian.

- Conflict: konflik yang timbul antar-anggota keluarga dan bisnis.

- Shared values and tradition: nilai-nilai dan tradisi keluarga.

3. Kinerja Perusahaan Keluarga

Definisi luas dari kinerja bisnis sendiri dapat dilihat melalui dua sisi: kinerja finansial dan non-finansial (Mokhber et al., 2017). Indikator dalam variabel ini adalah sebagai berikut. 
- Return on investment (ROI): rasio pendapatan atas investasi perusahaan.

- Sales growth: pertumbuhan tingkat penjualan perusahaan.

- Market share: bagian pasar yang dikuasai perusahaan.

- Product/service quality: kualitas dari produk atau jasa yang ditawarkan perusahaan.

- Operational efficiency: Efisiensi kegiatan operasional yang dilakukan perusahaan.

\subsection{Metode Analisis dan Pengujian Hipotesis}

Metode analisis yang akan digunakan dalam penelitian ini adalah structural equation modeling (SEM) berbasis varians partial least square (PLS). SEM-PLS adalah analisis persamaan struktural (SEM) berbasis varian di mana secara simultan dapat melakukan pengujian model pengukuran sekaligus pengujian model struktural (Abdillah \& Jogiyanto, 2015).

\section{Hasil dan Pembahasan}

Hasil pengumpulan data dari penelitian ini berjumlah 93 orang responden. Data responden menunjukkan bahwa responden dari penelitian ini berusia 19-27 tahun, sedangkan usia perusahaan keluarga responden berusia 2-54 tahun. Mayoritas responden merupakan generasi kedua dari perusahaan keluarga masing-masing responden. Domisili responden mayoritas berasal dari Kota Surabaya yang berjumlah 24 orang. Badan usaha perusahaan milik responden beragam, selain itu juga ada perusahaan yang belum memiliki atau belum mengurus badan usaha.

\subsection{Uji Validitas dan Reliabilitas}

Uji validitas menunjukkan faktor loading beberapa indikator dalam variabel hubungan antar-anggota keluarga dan bisnis belum memenuhi syarat uji validasi, hal ini mengartikan bahwa indikator-indikator tersebut tidak cocok digunakan untuk objek penelitian ini. Factor loading dengan nilai $>0,5$ dapat dipertahankan jika average variance extracted (AVE) telah mencapai $>0,5$ (Abdillah \& Jogiyanto, 2015). Indikator yang dihapus adalah $\mathrm{X}_{2.4}$ (loyalty), $\mathrm{X}_{2.5}$ (family turmoil), $\mathrm{X}_{2.6}$ (sibling rivalry, $\mathrm{X}_{2.7}$ (jealousy/resentment), dan $\mathrm{X}_{2.8}$ (conflict). Setelah penyesuaian, nilai factor loading dan AVE semua indikator memenuhi syarat. Nilai cronbach's alpha dan composite reliability juga telah memenuhi syarat.

\subsection{Pengujian Hipotesis}

Uji model struktural (inner model) dilakukan dengan melihat nilai t-statistik dan R2 pada hasil bootstrapping. Skor nilai t-statistik harus di atas 1,64 untuk hipotesis satu ekor (onetailed) untuk pengujian alpha 5 persen (Hair et al., 2008 dalam Abdillah \& Jogiyanto, 2015). Tingkat kesiapan suksesor memiliki pengaruh positif dan signifikan terhadap kinerja perusahaan keluarga dengan nilai t-statistik 1,726. Hal ini menunjukkan bahwa hipotesis pertama dari penelitian ini "tingkat kesiapan suksesor berpengaruh positif dan signifikan terhadap kinerja perusahaan keluarga" dapat diterima.

Hubungan antar-anggota keluarga dan bisnis memiliki pengaruh positif dan signifikan terhadap kinerja perusahaan keluarga dengan nilai t-statistik 8,094 karena melebihi t-hitung 1,64. Hal ini menunjukkan bahwa hipotesis kedua dari penelitian ini "hubungan antar-anggota keluarga dan bisnis berpengaruh positif dan signifikan terhadap kinerja perusahaan keluarga" dapat diterima.

Uji $\mathrm{R}^{2}$ menunjukkan nilai 0,386 menunjukkan bahwa variansi perubahan variabel kinerja perusahaan keluarga dapat dijelaskan sebanyak 
38,6\% oleh tingkat kesiapan suksesor dan hubungan antar-anggota keluarga dan bisnis.

\subsection{Pembahasan}

Hasil uji hipotesis menunjukkan bahwa tingkat kesiapan suksesor berpengaruh positif dan signifikan terhadap kinerja perusahaan keluarga. Temuan ini menunjukkan bahwa semakin tinggi tingkat kesiapan suksesor dalam sebuah perusahaan keluarga, maka kinerja perusahaan keluarga juga akan meningkat. hasil ini didukung oleh penelitian sebelumnya oleh Mokhber et al. (2017) yang mengatakan tingkat kesiapan suksesor memberi pengaruh positif pada kinerja perusahaan keluarga.

Suksesor yang tergabung dalam Family Business Community Universitas Ciputra harus terus belajar, menambah pengalaman, dan mempersiapkan diri agar kinerja perusahaan keluarga dapat terus terjaga. Suksesor yang siap akan memastikan kinerja perusahaan keluarga dapat berjalan. Ramadani et al. (2017) mengatakan berbagai macam metode dilakukan pendiri perusahaan dalam memfasilitasi suksesor, salah satunya adalah memberi akses untuk pendidikan, suksesor harus dibekali pengetahuan dan pengalaman sebelum mengatur perusahaan keluarga secara langsung.

Hubungan antar-anggota keluarga dan bisnis berpengaruh positif dan signifikan terhadap kinerja perusahaan keluarga. Maka dapat dikatakan dalam konteks perusahaan keluarga, semakin baik hubungan dalam keluarga, kinerja perusahaan keluarga juga akan meningkat. Hasil penelitian ini memiliki kesamaan dengan temuan oleh Mokhber et al. (2017).

Hubungan yang baik dalam keluarga harus dapat dijaga oleh perusahaan keluarga guna meningkatkan kinerja perusahaan keluarga, selain hubungan incumbent dengan suksesor, hubungan dengan anggota keluarga lain juga merupakan hal yang penting dalam sebuah perusahaan keluarga.
Maciel et al. (2015) mengatakan hubungan keluarga merupakan aspek yang penting untuk kesuksesan sebuah perusahaan keluarga.

\subsection{Implikasi Hasil Penelitian}

Penelitian ini menunjukkan bahwa setiap perusahaan keluarga harus memperhatikan tingkat kesiapan dari tiap suksesor yang potensial dan hubungan yang ada di dalam keluarga agar kinerja perusahaan keluarga yang ada dalam komunitas tetap terjaga. Hal ini dapat dilakukan dengan meningkatkan kepedulian generasi sebelumnya (incumbent) terhadap calon generasi penerus (successor), sehingga generasi penerus siap dalam proses suksesi yang akan dilakukan dan menjaga Kinerja Perusahaan Keluarga. Suksesor harus dipersiapkan dengan sungguh-sungguh untuk menyalurkan potensi diri dan berkontribusi untuk perusahaan keluarga.

Suksesor perlu untuk mempersiapkan diri untuk meneruskan perusahaan keluarga mereka masing-masing. Self-perception juga tidak lepas dari salah satu aspek yang harus disiapkan suksesor. Persepsi individu setiap suksesor harus menganggap diri mereka siap agar muncul rasa percaya diri dan menjaga kinerja perusahaan keluarga stabil atau meningkat.

Hubungan yang baik dalam keluarga perlu diperhatikan dalam sebuah perusahaan keluarga. Keluarga dan bisnis merupakan suatu kesatuan yang mana salah satu di antaranya tidak dapat dilupakan. Keluarga harus dapat saling terbuka, meningkatkan kepercayaan satu sama lain dan juga saling berbagi nilai-nilai dan tradisi yang dimiliki.

\section{Kesimpulan}

Berdasarkan hasil analisis dan penelitian yang telah dilakukan maka kesimpulan dari penelitian ini adalah sebagai berikut. 
1. Tingkat kesiapan suksesor berpengaruh positif dan signifikan terhadap kinerja perusahaan keluarga.

2. Hubungan antar-anggota keluarga dan bisnis berpengaruh positif dan signifikan terhadap kinerja perusahaan keluarga.

Perusahaan keluarga harus dapat mempersiapkan calon suksesor yang potensial bagi perusahaan agar keberlanjutan bisnis tetap terjaga. Selain ini tantangan lain yang ada dalam perusahaan keluarga adalah hubungan keluarga yang saling beririsan dengan urusan bisnis. Keluarga harus dapat menjaga hubungan yang baik agar kinerja perusahaan keluarga juga berjalan stabil.

\section{Saran}

Perusahaan keluarga dapat lebih mempertimbangkan untuk persiapan suksesor yang lebih matang. Selain itu, perusahaan keluarga juga harus menjaga erat hubungan antar-anggota keluarga dan bisnis masing-masing, agar kinerja perusahaan tetap berlangsung lebih baik dan optimal.

Peneliti selanjutnya dapat menyempurnakan variabel-variabel yang digunakan dalam penelitian ini dan melakukan penelitian dalam populasi yang berbeda. Peneliti selanjutnya dapat mengeksplorasi kembali indikator-indikator dalam penelitian ini. Perhitungan Kinerja Perusahaan Keluarga dapat dilakukan lebih objektif untuk menghindari jawaban yang bias.

\section{Keterbatasan Penelitian}

Sampel yang digunakan dalam penelitian ini tidak mencakup sebagian besar populasi yang ada.

Pengukuran variabel menggunakan kuesioner dapat menghasilkan jawaban yang subjektif.

\section{LAMPIRAN}

\section{Output PLS}

Loading faktor sebelum penyesuaian

\begin{tabular}{|c|c|c|c|}
\hline \multicolumn{4}{|c|}{ Outer Loadings } \\
\hline \multicolumn{4}{|l|}{ Matrix } \\
\hline & X1 Tingkat Kesi... & X2 Hubungan ... & Y Kinerja Perus... \\
\hline $\mathrm{X} 1$ & 1.000 & & \\
\hline X2.1 & & 0.665 & \\
\hline $\mathrm{X} 2.2$ & & 0.569 & \\
\hline $\mathrm{X} 2.3$ & & 0.670 & \\
\hline$\times 2.4$ & & 0.591 & \\
\hline X2.5 & & 0.595 & \\
\hline $\mathrm{X} 2.6$ & & 0.429 & \\
\hline $\mathrm{X} 2.7$ & & 0.604 & \\
\hline $\mathrm{X} 2.8$ & & 0.639 & \\
\hline X2.9 & & 0.708 & \\
\hline X3.1 & & & 0.791 \\
\hline $\mathrm{X} 3.2$ & & & 0.769 \\
\hline $\mathrm{X} 3.3$ & & & 0.745 \\
\hline X3.4 & & & 0.691 \\
\hline X3.5 & & & 0.660 \\
\hline
\end{tabular}

Loading faktor setelah penyesuaian

\section{Outer Loadings}

\begin{tabular}{|c|c|c|c|}
\hline \multirow[t]{2}{*}{ Matrix } & & & \multirow[b]{2}{*}{ Y Kinerja Perus... } \\
\hline & X1 Tingkat Kesi... & X2 Hubungan ... & \\
\hline $\mathrm{X} 1$ & 1.000 & & \\
\hline X2.1 & & 0.712 & \\
\hline$X 2.2$ & & 0.623 & \\
\hline$X 2.3$ & & 0.708 & \\
\hline$X 2.9$ & & 0.824 & \\
\hline$X 3.1$ & & & 0.778 \\
\hline X3.2 & & & 0.755 \\
\hline X3.3 & & & 0.751 \\
\hline $\mathrm{X} 3.4$ & & & 0.696 \\
\hline X3.5 & & & 0.677 \\
\hline
\end{tabular}


Konstruk validitas dan reliabilitas

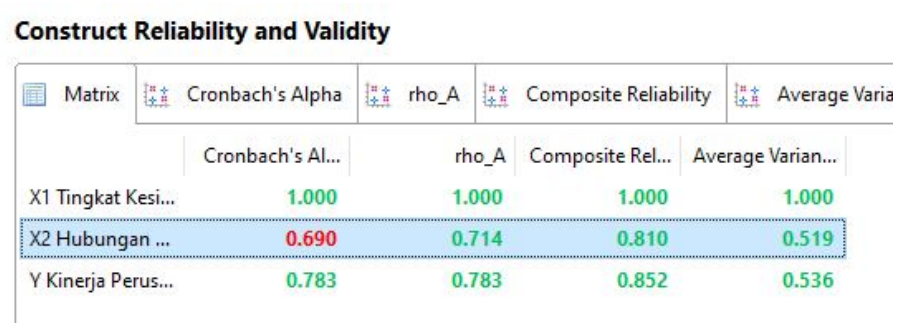

Nilai $R^{2}$

\section{R Square}

\begin{tabular}{|c|c|c|c|c|c|}
\hline \multirow[t]{2}{*}{ Matrix } & 接亲 R Square & 接素 & \multicolumn{2}{|c|}{ R Square Adjusted } & \\
\hline & & & R Square & & Square Adjus... \\
\hline \multicolumn{3}{|c|}{ Y Kinerja Perusahaan Keluarga } & 0.386 & & 0.373 \\
\hline
\end{tabular}

\section{$\mathrm{t}$-statistik dan nilai $\mathrm{p}$}

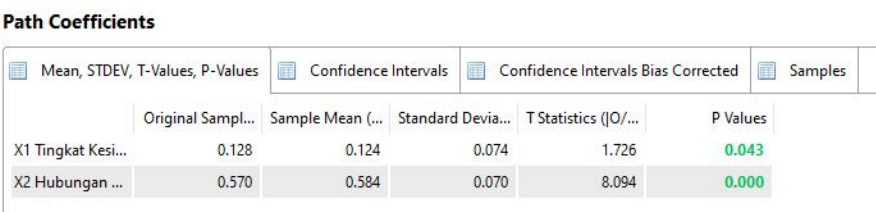

\section{DAFTAR RUJUKAN}

Abdillah, W. \& Jogiyanto. 2015. Partial Least Square (PLS) Alternatif Structural Equation Modeling (SEM) dalam Penelitian Bisnis.

Aronoff, C.E. \& Ward, J.L. 1995. Family-Owned Businesses: A Thing of the Past or a Model for the Future? Family Business Review, 8(2), 121-130. https://doi.org/ 10.1111/j.1741-6248.1995.00121.x.

Bachkaniwala, D., Wright, M., \& Ram, M. 2001. Succession in South Asian Family Businesses in the UK. International Small Business Journal: Researching Entrepreneurship, 19(4), 15-27. https://doi.org/10.1177/ 0266242601194001.
Barach, J.A. \& Ganitsky, J.B. 1995. Successful Succession in Family Business. Family Business Review, 8(2), 131-155. https://doi.org/ 10.1111/j.1741-6248.1995.00131.x.

Bizri, R. 2016. Succession in the Family Business: Drivers and Pathways. International Journal of Entrepreneurial Behaviour and Research, 22(1), 133-154. https://doi.org/ 10.1108/IJEBR-01-2015-0020.

Bozer, G., Levin, L., \& Santora, J.C. 2017. Succession in family business: multi-source perspectives. Journal of Small Business and Enterprise Development, 24(4), 753-774. https://doi.org/10.1108/JSBED-10-20160163.

Buang, N.A., Ganefri, \& Sidek, S. 2013. Family Business Succession of SMEs and PostTransition Business Performance. Asian Social Science, 9(12 SPL ISSUE), 79-92. https://doi.org/10.5539/ass.v9n12p79.

Chin, W.W. 1998. The Partial Least Squares Approach to Structural Equation Modeling. Modern Methods for Business Research. London.

Chu, W. 2011. Family Ownership and Firm Performance: Influence of Family Management, Family Control, and Firm Size. Asia Pacific Journal of Management, 28(4), 833851. https://doi.org/10.1007/s10490-0099180-1.

Diéguez-Soto, J., López-Delgado, P., \& RojoRamírez, A. 2015. Identifying and Classifying Family Businesses. Review of Managerial Science, 9(3), 603-634. https:// doi.org/10.1007/s11846-014-0128-6.

Ghee, W.Y., Ibrahim, M.D., \& Abdul-Halim, H. 2015. Family Business Succession Planning: Unleashing the Key Factors of Business Performance. Asian Academy of Management Journal, 20(2), 103-126. 
Kamei, K. \& Dana, L.P. 2012. Examining the Impact Of New Policy Facilitating SME Succession in Japan: from a Viewpoint of Risk Management in Family Business. International Journal of Entrepreneurship and Small Business, 16(1), 60. https://doi.org/ 10.1504/IJESB.2012.046917.

Kim, Y. \& Gao, F.Y. 2013. Does Family Involvement Increase Business Performance? Family-Longevity Goals' Moderating Role in Chinese Family Firms. Journal of Business Research, 66(2), 265-274. https://doi.org/ 10.1016/j.jbusres.2012.08.018.

Maciel, A.S., Ramos, M.I. de la G., Aguilar, J.L.E., \& Reyna, J.M.S.M. 2015. The Influence of Family Relationships in the Succession: A Factorial Analysis of Mexican Enterprises. Journal of Family Business Management, 5(2), 238-256.

Mokhber, M., Gi Gi, T., Abdul Rasid, S.Z., Vakilbashi, A., Mohd Zamil, N., \& Woon Seng, Y. (2017). Succession Planning and Family Business Performance in SMEs. Journal of Management Development, 36(3), 330-347. https://doi.org/10.1108/ JMD-12-2015-0171.

Morris, M.H., Williams, R.W., \& Nel, D. 1996. Factors Influencing Family Business Succession. International Journal of Entrepreneurial Behavior \& Research, 2(3), 68-81. https://doi.org/10.1108/135525596101532 61.

Motwani, J., Levenburg, N.M., Schwarz, T.V., \& Blankson, C. 2006. Succession Planning in SMEs: An Empirical Analysis. Inter- national Small Business Journal, 24(5), 471495. https://doi.org/10.1177/026624260 6067270 .

Price Waterhouse Cooper. 2014. Survey Bisnis Keluarga 2014. (November), 1-35. Retrieved from https://www.pwc.com/id/en/ publications/assets/indonesia-report-family-business-survey-2014.pdf.

Pyromalis, V.D. \& Vozikis, G.S. 2009. Mapping the Successful Succession Process in Family Firms: Evidence from Greece. International Entrepreneurship and Management Journal, 5(4), 439-460. https://doi.org/ 10.1007/s11365-009-0118-3.

Ramadani, V., Hisrich, R.D., Anggadwita, G., \& Alamanda, D.T. 2017. Gender and Succession Planning: Opportunities for $\mathrm{Fe}-$ males to Lead Indonesian Family Businesses. International Journal of Gender and Entrepreneurship, 9(3), 229-251. https://doi.org/10.1108/IJGE-02-20170012.

Setiawan, B.R. \& Susanto, H. 2018. Perencanaan Suksesi pada Perusahaan Keluarga di Universitas Ciputra Surabaya. Jurnal Manajemen dan Start-Up Bisnis, 2(6), 690-696.

Venkatraman, N. \& Ramanujam, V. 1986. Measurement of Business Performance in Strategy Research: A Comparison of Approaches. The Academy of Management Review, 11(4), 801. https://doi.org/10.2307/ 258398.

Walsh, G. 2011. Family Business Succession. Managing the All Important Family Component. Kpmg Enterprise, 70. 
Accounting and Management Journal, Vol. 3, No. 2, December 2019 